\title{
Research on Surrounding Rock Control Technology of Roadway Excavated in Residual Coal Pillar
}

\author{
Donghai Jiang \\ Shandong University of Science and \\ Technology \\ Qingdao, China \\ esriver@163.com \\ Yuanjie Wang \\ Taiyuan University of Technology \\ Taiyuan, China \\ vollxyz989@163.com
}

\author{
Tongxu Wang \\ Shandong University of Science and \\ Technology \\ Qingdao, China \\ wtx6383@163.com
}

\author{
Mingguang Zhang \\ Shandong University of Science and \\ Technology \\ Qingdao, China \\ zmg1981@163.com
}

\begin{abstract}
In order to research surrounding rock control technology of roadway excavated in residual coal pillar, this article took excavation roadway in coal pillar that was between the two parallel empty roadways as the research background , used field investigation, theoretical analysis and calculation, similar material grouting test, numerical simulation analysis, field engineering application and other methods, Analyzed stress state in pillar when excavating in coal pillar; analyzed grouting reinforcement mechanism of cracked coal-rock mass the consolidation body strength and analyzed the diffusion radius of slurry through three-dimension broken coal-rock mass grouting changing performance system developed independently; researched stress and deformation damage of roadway surrounding rock after bolt-grouting through using numerical simulation software FLAC3D. Through field practice we can draw: that damage depth and deformation of roadway surrounding rock decreased through using boltgrouting support way, besides, anchor and anchor cable can play a role effectively, bolt-grouting support can improve stability of roadway surrounding rock effectively.
\end{abstract}

Keywords - old mining, residual coal pillar, grouting changing performance system, surrounding rock control, boltgrouting support

\section{INTRODUCTION}

Mining was limited by the level of technology in the last century, and many coal mines used room and pillar mining methods to mine[1-3], these methods would leave many mine resources. In order to repeat mining efficiently, should excavate roadway in repeated mining area firstly, while old mining methods formed many empty roadways and different forms of coal pillars. When excavating roadways through these areas, research the failure of surrounding rock and put forward a reasonable roadway support program will be one of the key technologies of residual coal repeated mining. So, the title that research on surrounding rock control mechanism of roadway excavated in residual pillar has important theoretical and practical significance.

Many scholars had conducted a series of studies on the excavation roadway in coal pillars, but these studies mainly remained in theoretical aspects [4-5] and numerical simulations [6-7].This article took residual coal repeated mining in Xucun coal mine as the research background. Through field investigation, theoretical analysis and calculation, similar material grouting test, numerical simulation analysis, field engineering application and other methods, researched on surrounding rock control technology of roadway excavated in coal pillar that was between the two parallel empty roadways which were left by old mining, this research provided a certain theoretical basis and construction measures for support of roadway surrounding rock under such condition.

\section{PROJECT BACKGROUND}

The repeated mining work face was located in $3 \#$ coal seam of Xucun coal mine, 3\# coal seam was buried depth in $220 \mathrm{~m}$ and its thickness was about $2.8 \mathrm{~m}$, figure 1 was repeated mining work face layout. Old mining area left two empty roadways, there was a $7 \mathrm{~m}$ wide coal pillar during these two empty roadways, the roadway of repeated mining work face was arranged in residual coal pillar. The abutment stress in coal pillar was increased as far away from the coal wall, therefore, coal wall plastic failure had occurred within a certain range from the edge of the coal wall. Apply limit equilibrium theory and formula 1[8], can calculate the width of plastic area.

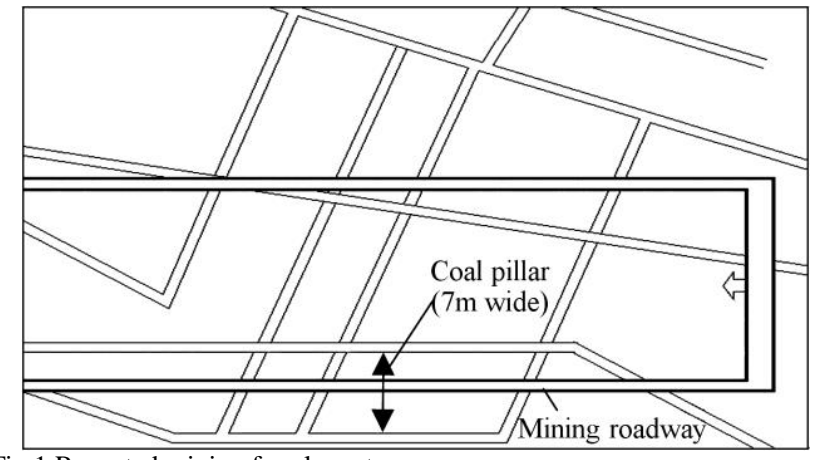

Fig.1 Repeated mining face layout

$$
x_{0}=\frac{m A}{2 \tan \theta_{0}} \ln \left[\frac{K \gamma H+\frac{C}{\tan \theta_{0}}}{\frac{P}{A}+\frac{C}{\tan \theta_{01}}}\right]
$$

Where, $x_{0}$-seam thickness, 2.8m; $A$-coefficient of horizontal pressure, $1.1 ; \theta_{0}-$ coal friction angle, $30^{\circ}$; $K$-stress concentration factor, $3 ; \gamma$-bulk density of overlying rock, $2.5 \mathrm{t} / \mathrm{m}^{3} ; H$-burial depth of coal seam, 
220m; $C$-coal cohesion, $0.4 \mathrm{MPa} ; \quad P$-resistance of support to coal wall, 0 。

Calculated by formula 1 , empty roadway which was leaved in old mining area made $8.5 \mathrm{~m}$ wide plastic area, the plastic area was wider than coal pillar, so, the repeating roadway was arranged in plastic pillar.

\section{STRESS DISTRIBUTIONS IN COAL PILLAR}

Under the effect of overburden load, the stress of coal pillar was greater than the original rock stress, therefore, the

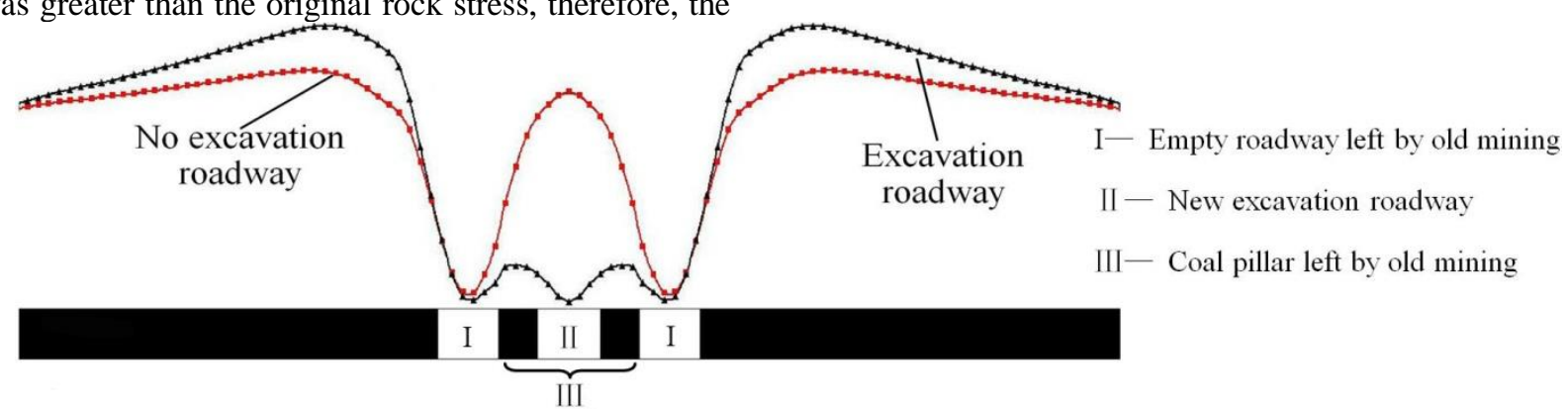

Fig.2 Coal pillar stress graph

For the larger area mined by old mining, the more caving gangue was, the more deformation of roof and floor was, causing caving gangue in goaf touched the roof. So, used the formula 2 to calculate the coal pillar load[11].

$$
p=\gamma H\left[1+\frac{b}{2 a}\left(2-\frac{b}{0.6 H}\right)\right]
$$

Thus, $p$ - pillar load, MPa; $a, b$-width of coal pillar, width of roadway, took $7 \mathrm{~m}, 3 \mathrm{~m}$.

Calculated by formula 2, the load on residual pillar was 6.6MPa, the stress concentration factor was $\mathrm{K}=1.2$.

Excavating roadway in residual plastic pillar, the new roadway and the empty roadways constituted roadway group. The more denser of roadway was, the more larger of abutment stress was, when the residual coal pillar was destroyed due to its small size, the load on the coal pillar would be transferred to the adjacent coal pillar, if the adjacent pillar was also damaged under the superimposed load, there would be a wide range of pressure arch in which overburden strata can move. In the research content of this article, the coal pillar was damaged, and the load on the coal pillar was transferred to the side of the solid coal.

It can be seen from figure 2 that the maximum stress concentration factor of coal pillar load reached 1.2 when no roadway had been excavated in the remaining coal pillar; when the roadway was excavated in coal pillar, the bearing stress in the remaining coal pillar became smaller. The load was transferred to the side of the solid coal. Due to stress transfer, the maximum stress concentration factor in the solid coal was greater than the maximum stress concentration factor that there was no roadway. stress concentration phenomenon was happened in coal pillar; while two sides of coal pillar were not bound by lateral pressure, so, the compressive strength of these areas was more low and failure had occurred more easily; then, concentrated stress transferred into coal pillar inside. Because of the superposition of abutment stress in coal pillar inside, the largest vertical stress was supported by the center of coal pillar, and it was larger than rock stress, the vertical stress on the whole pillar appear "arch" distribution[9-10], as was shown in figure 2 .

\section{ANALYSIS ON MECHANICAL PROPERTIES OF GROUTING REINFORCEMENT IN PLASTIC COAL-ROCK MASS}

Due to the plastic failure of the coal pillar, the stability and load carrying capacity were extremely low. When roadway was excavated in the coal pillar and the surrounding rock of the roadway was supported by anchors, the anchors were all in the broken surrounding rock, and the anchors had no force foundation and the anchorage force was very small, it can't maintain the stability of the surrounding rock of roadway. Therefore, if excavating the roadway in this case, using the support method of bolt-grouting to support surrounding rock of the roadway was adopted.

During grouting construction, the cement slurry was infiltrated into the fractured coal-rock mass cracks under the action of the pressure of the grouting pump, and the cracks in the fractured coal-rock mass were filled and enriched. Due to the bond effect of the slurry, the fractured coal-rock mass was consolidated again and it formed a consolidation body that can play bearing capacity. Through the grouting to coalrock mass, the strength and mechanical properties of coalrock mass had been improved, so as to enhance the bearing capacity of surrounding rock of the roadway.

In order to study the mechanical properties of roadway surrounding rock mass which grouted, used self-developed three-dimension grouting experiment system of changing performance of broken coal-rock mass, it included grouting test-bed, grouting system and visualization system of grouting diffusion range, figure 3 was the connection of each part. 


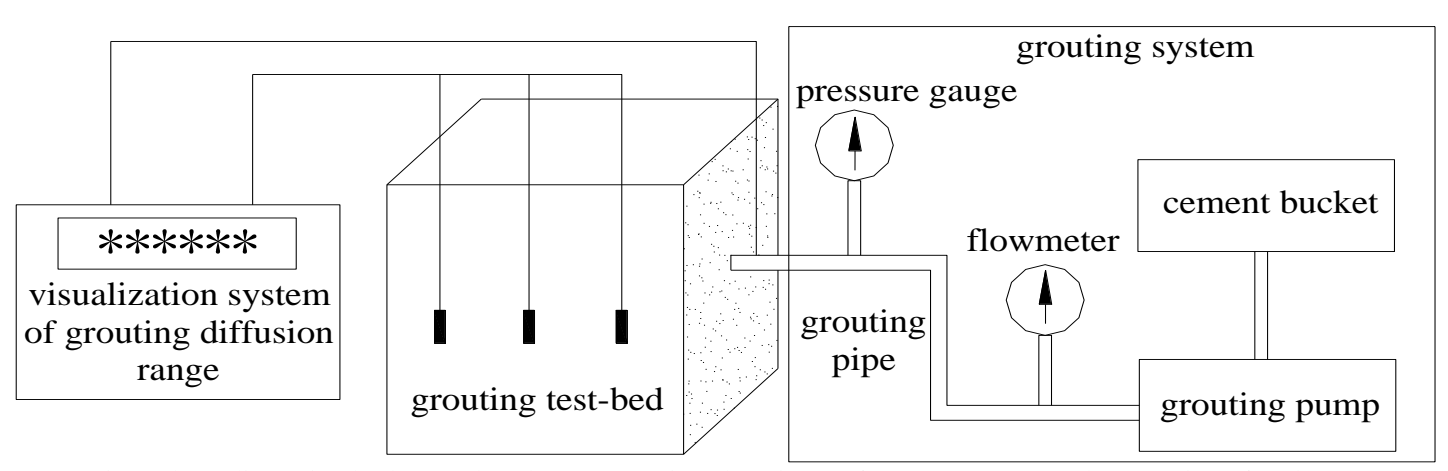

Fig.3 Three-dimension broken coal-rock mass grouting changing performance system and connection of each part

The grouting test-bed's size was $0.5 \mathrm{~m} \times 0.5 \mathrm{~m} \times 0.5 \mathrm{~m}$, it's frame was welded by angle steel and was surrounded by tempered glass, in the middle of tempered glass of one side of the test-bed had a grouting hole, the bottom of the test-bed was a piece of wood, on the wood there were five slurry overflow holes, and the test-bed was mounted on a base welded by angle steel.

The grouting system included cement bucket, grouting pump, pressure gauge, flow meter, grouting pipe, stop valve, hole packer and so on. Grouting pump was manual pressure grouting pump of MG-808 type. The pressure gauge and flow meter were installed on the grouting pipe which was installed on slurry outlet, they can measure the grouting pressure and grouting volume.

The visualization system of grouting diffusion range was a self-developed visualization system for monitoring slurry conditions in the laboratory, it can monitor the slurry diffusion range during grouting, the diffusion time of the slurry to the sensor and the diffusion pressure of the slurry at the sensor. The sensors of the visualization system were embedded in grouting test-bed during laying the broken coalrock material. During the grouting experiment, once the slurry had spread to the sensor position, the corresponding signal light in the visualization system lighted up, and then the distance between the sensor's position and the grouting port, the time and pressure at which the slurry flowed to the sensor can be recorded. The visualization system of grouting diffusion range was shown in figure 4 .

The grouting experiment of roadway surrounding rock was carried out according to the matching ratio of similar materials simulation experiment[12]. The similar materials were gravels of different sizes, the slurry material was cement slurry, the grouting pressure was $0.25 \mathrm{MPa}$, and the slurry water-cement ratio was $0.8: 1$. After the grouting was completely and all the slurry had solidified, a uniaxial compression test was performed on cores at different locations in the surrounding rock of the roadway. The core test was shown in figure 5, and the mechanical parameters of the surrounding rock of the roadway after grouting reinforcement were tested, the test results were shown in table 1.

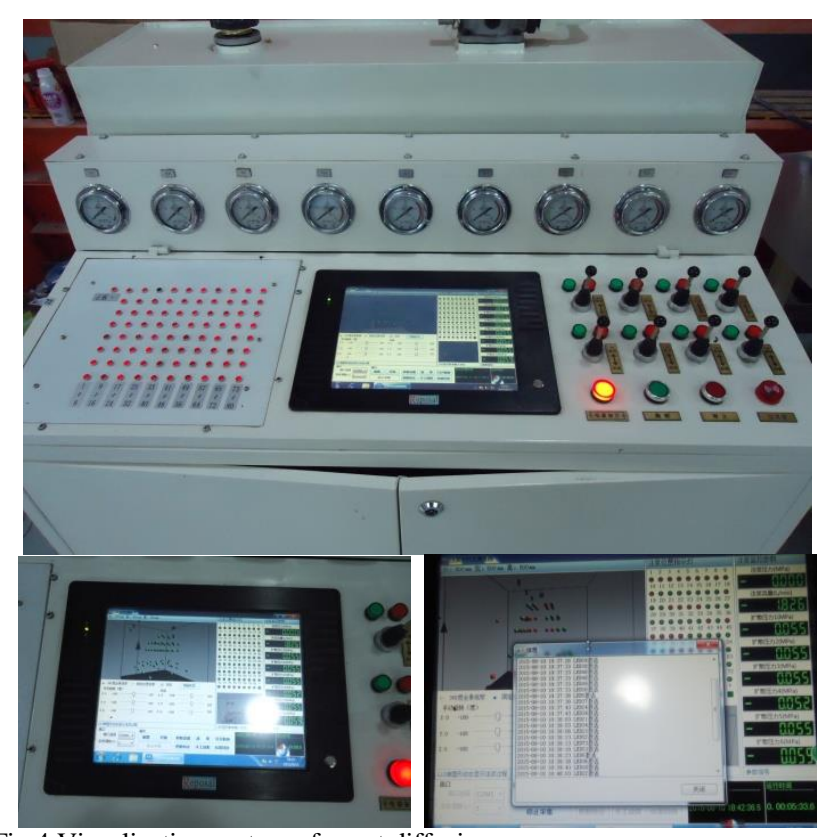

Fig.4 Visualization system of grout diffusion range

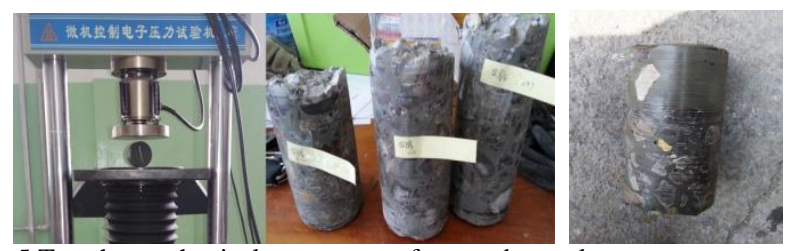

Fig.5 Test the mechanical parameters of grouted gravel core

It can be seen from table 1 that the strength of the mechanical parameters of the specimen was higher, and the strength of the grouting consolidation body was increased because the slurry entered into the fractured coal-rock mass and caused the properties of the coal-rock mass to change. The first reason was that the grouting slurry improved the mechanical properties of the weak face of the fractured coalrock mass, reduced the sliding ability of the coal-rock mass between the weak faces, and improved the tensile strength, shear strength, and other strength parameters of the fractured coal-rock mass; the second reason was that the slurry entered into the fractures of the coal-rock mass and filled the cracks and voids of the fractured coal-rock mass, because of the bond effect of the slurry, the fractured coal-rock mass became a load-bearing consolidation body that can play bearing capacity, the cohesive force and internal friction angle of the coal-rock mass were improved and the consolidation body after grouting was difficult to be destroyed. 
TABLE I. SPECIMEN MECHANICAL PARAMETERS

\begin{tabular}{|c|c|c|c|c|c|c|c|c|c|}
\hline Distance from working face $/ \boldsymbol{m}$ & 80 & 60 & 40 & 25 & 4 & 0 & -4 & -16 & -36 \\
\hline Working face advancing steps $/ \mathrm{m}$ & 16 & 36 & 56 & 71 & 92 & 96 & 100 & 112 & 136 \\
\hline Normal stress $\sigma_{\mathrm{a}} / \mathrm{MPa}$ & 30.76 & 32.35 & 36.98 & 49.25 & 50.43 & 22.03 & 74.38 & 48.27 & 47.68 \\
\hline Shear stress $\tau_{\mathrm{a}} / \mathrm{MPa}$ & 5.877 & 5.477 & 6.920 & 15.81 & 10.55 & 12.66 & 19.92 & 5.225 & 3.616 \\
\hline $\tan \alpha$ & 0.191 & 0.169 & 0.187 & 0.321 & 0.209 & 0.575 & 0.268 & 0.108 & 0.001 \\
\hline
\end{tabular}

\begin{tabular}{|c|c|c|c|c|c|}
\hline Specimen number & Compressive strength/MPa & Poisson ratio & Elastic modulus/GPa & Cohesion/MPa & Friction angle/ ${ }^{\circ}$ \\
\hline 1 & 8.60 & 0.31 & 17.05 & 6.00 & $38.83^{\circ}$ \\
\hline 2 & 7.90 & 0.29 & 16.35 & 5.60 & $48.50^{\circ}$ \\
\hline 3 & 9.70 & 0.31 & 19.2 & 6.50 & $30.64^{\circ}$ \\
\hline
\end{tabular}

\section{STUDY ON NUMERICAL SIMULATION OF BOLT-GROUTING SUPPORT IN SURROUNDING ROCK OF ROADWAY}

The bolt-grouting support was to grouting reinforcement of the roadway surrounding rock, and then used anchors and anchor cables to support the surrounding rock of the roadway[13]. The cement slurry was injected into the fractured surrounding rock mass and the mechanical parameters of the surrounding rock were improved. The anchors were all located in the reinforced surrounding rock and had a force foundation, the surrounding rock in anchorage zone formed by anchors composed compressedcombined arch and the compressed-combined arch was suspended in a stable rock formation above the roadway through the anchor cables. The mechanism of action was shown in figure 6.

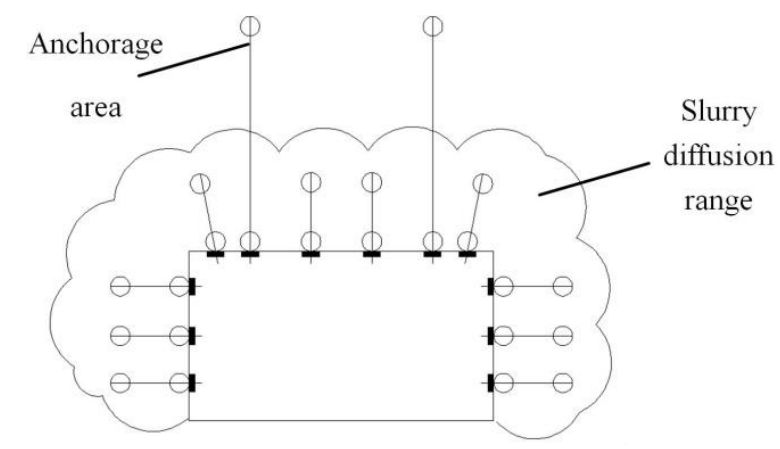

Fig.6 Bolt-grouting mechanism
After the grouting reinforcement was adopted, the physical and mechanical properties of the surrounding rock of the roadway were improved due to the effect of the slurry, and the integrity of the fractured coal-rock mass and the bearing capacity were also improved. When the grouting pressure was $0.25 \mathrm{MPa}$ and the water-cement ratio of the slurry was $0.8: 1$, the slurry diffusion radius which was measured by slurry diffusion radius monitoring system was $2.5 \mathrm{~m}$. In the numerical simulation calculation, the rock mechanics parameters of the surrounding rock within the range of $2.5 \mathrm{~m}$ of the roadway was properly adjusted according to the rock mechanical parameters after grouting reinforcement in order to simulate the stress and deformation of the roadway surrounding rock after grouting. The length, width, and height of the numerical simulation model were $86 \mathrm{~m}, 40 \mathrm{~m}$, and $26 \mathrm{~m}$ respectively, and the buried depth was $220 \mathrm{~m}$. The size of the empty roadway left from the old mining was width $\times$ height $=3 \mathrm{~m} \times 2.8 \mathrm{~m}$, and the width of the pillar between the two empty roadways was $7 \mathrm{~m}$, the bottom of the model limited the displacements in the $\mathrm{X}, \mathrm{Y}$, and $\mathrm{Z}$ directions, at the upper boundary of the model applied the load provided by the overburden. The simulation model had 22940 blocks and included 28500 nodes. The required mechanical parameters for each rock formation were shown in table 2. The model adopted the Mohr-Coulomb failure criterion to simulate the stress and failure deformation of surrounding rock of roadway excavated in remaining coal pillar with or without bolt-grouting support. The numerical simulation model was shown in figure 7.

TABLE II. ROCK MECHANICAL PARAMETERS

\begin{tabular}{|c|c|c|c|c|c|}
\hline Strata & Tensile strength/MPa & Poisson ratio & Elastic modulus/GPa & Cohesion/MPa & Friction angle $/^{\circ}$ \\
\hline Fine sandstone & 3.45 & 0.19 & 3.68 & 2.80 & 30.60 \\
\hline Sandstone & 4.97 & 0.30 & 5.68 & 3.94 & 32.60 \\
\hline Sandy mudstone & 3.49 & 0.28 & 4.04 & 2.98 & 25.30 \\
\hline Siltstone & 6.23 & 0.29 & 5.91 & 4.85 & 27.90 \\
\hline Carbon mudstone & 4.20 & 0.21 & 5.30 & 3.80 & 26.50 \\
\hline Coal & 0.28 & 0.27 & 0.36 & 0.40 & 30.00 \\
\hline
\end{tabular}

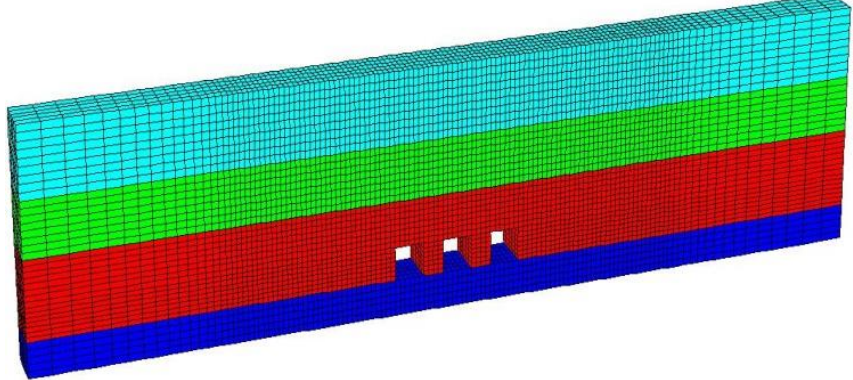

Simulated and analyzed the roadway surrounding rock stress and deformation damage under the support and unsupported conditions, extracted the simulation data, drew the coal pillar stress diagrams, as was shown in figure 8.

Fig.7 Numerical simulation model 


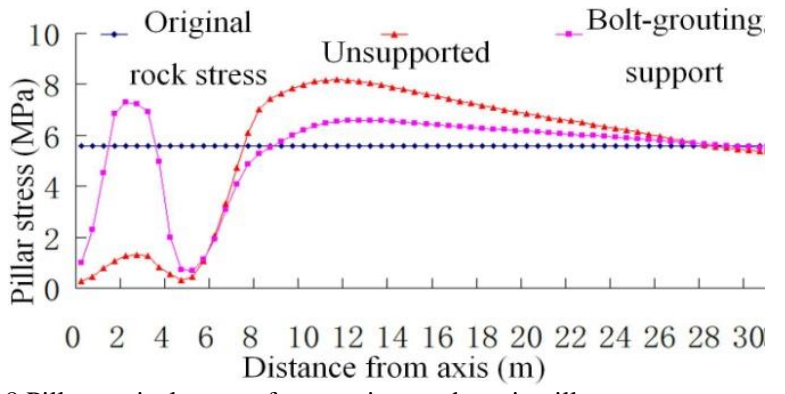

Fig.8 Pillar vertical stress of excavating roadway in pillar

As can be seen from figure 8, whether supported or unsupported, the change trend of the vertical stress on the coal pillar was consistent during excavating roadway in coal pillar, the stress increased from the axis of the roadway to both sides first, then decreased and then increased, finally, the stress tended to be stable. The difference was that the vertical stress value on the pillar was smaller before the pillar was supported while the vertical stress value was significantly increased after bolt-grouting support, the maximum vertical stress value on the coal pillar was increased from unsupported $1.3 \mathrm{MPa}$ to $7.3 \mathrm{MPa}$, and the stress concentration factor was 1.33; at the same time, the stress value in the solid coal side of the old mining remaining roadway was significantly reduced, the maximum vertical stress value was reduced from unsupported $8.2 \mathrm{MPa}$ to 6.2 $\mathrm{MPa}$, and the maximum stress concentration factor was reduced from 1.5 to 1.1 . By analyzing figure 8 , it can be concluded that due to the support of bolt-grouting, the ability of coal pillar to carry overburden load significantly improved, the coal pillar between the roadways and the solid coal jointly beard the overburden load.

Figure 9 reflected the depth of plastic failure before and after roadway support, and the support method was boltgrouting support.
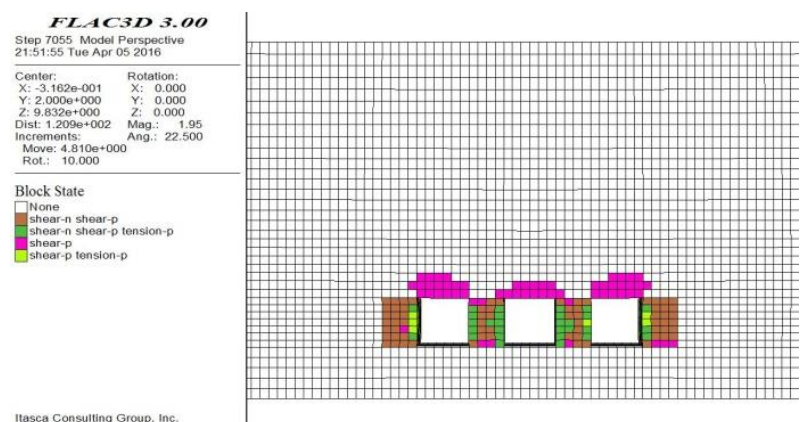

Mtasca Consulting Group, Inc
Minneapolis, MN USA

(a) Before support

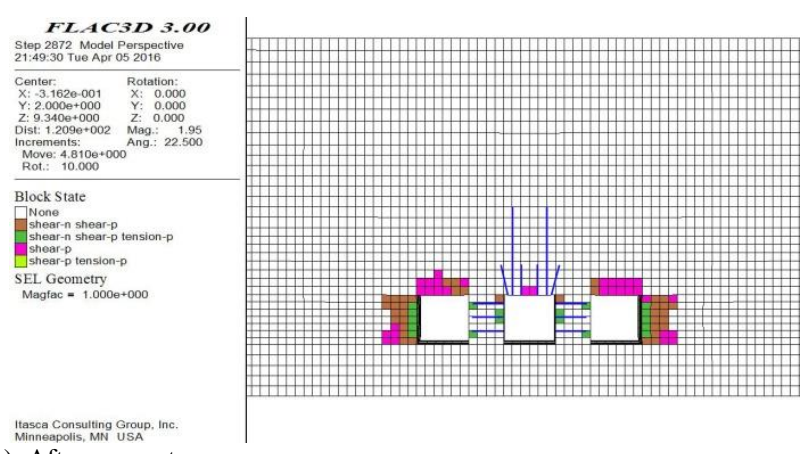

(b) After support

Fig.9 Surrounding rock damage of excavating roadway in coal pillar

It can be seen from figure 9 that under the condition of no support, the two sides of new excavation roadway were completely destroyed and the damage depth of the roof was about $2 \mathrm{~m}$; after the surrounding rock of roadway was boltgrouting supported, the slurry solidified the broken coal-rock mass and formed a consolidation body that had the bearing effect, the plastic area of the surrounding rock was significantly smaller, the roof of the new roadway was hardly damaged, the damage depth of the solid coal side of the empty roadway left from the old mining was also changed from the original $3.5 \mathrm{~m}$ to $2 \mathrm{~m}$. The smaller the failure depth of the solid coal side of the empty roadway, the greater the width of the pillar which supported the overlying rock load, and average load on coal pillar became smaller, this environment was more conducive to make the surrounding rock of roadway stable.

The simulation results were imported into Tecplot software to obtain the schematic diagram of horizontal and vertical displacement changes of roadway surrounding rock, as were shown in figure 10 .

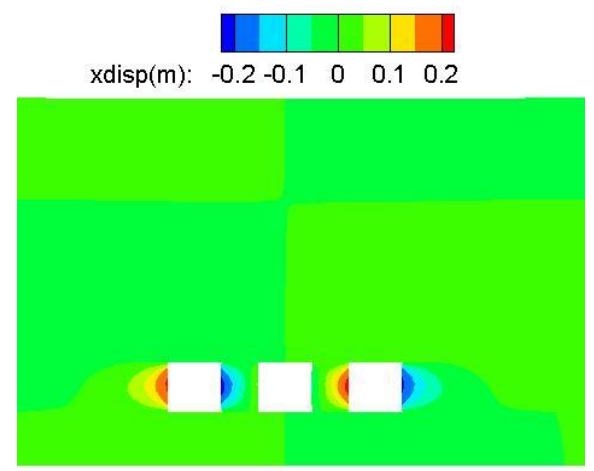

(a) Two sides displacement with before support

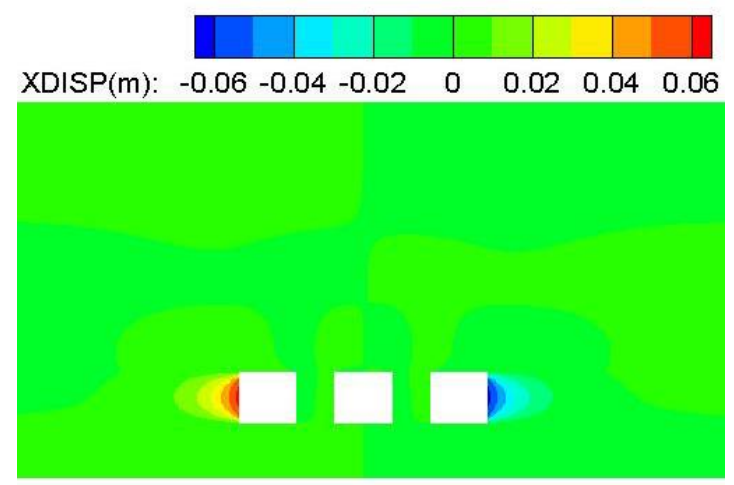

(b) Two sides displacement with after support

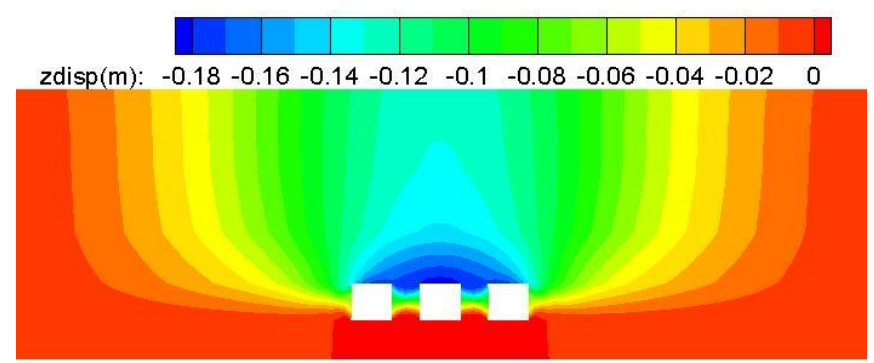

(c) Vertical displacement with before support 


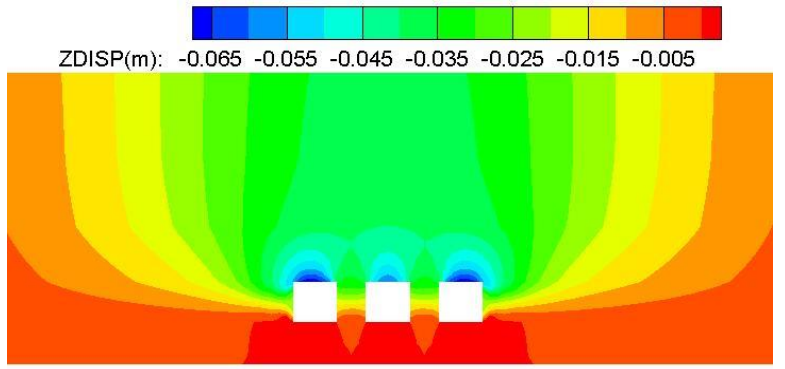

(d) Vertical displacement with after support

Fig.10 Surrounding rock displacement of excavating roadway in coal pillar

It can be seen from figure $10(a)(c)$ that before the roadway was supported, the horizontal displacement of the two sides of the roadway reached $400 \mathrm{~mm}$, and the amount of roof subsidence was about $180 \mathrm{~mm}$; it can be seen from figure 10(b)(d) that after bolt-grouting support, the horizontal displacement of the two sides of roadway was about $120 \mathrm{~mm}$ which was reduced by $70 \%$, and the amount of roof subsidence was about $65 \mathrm{~mm}$, which was reduced by $64 \%$.

\section{PROJECT EXAMPLE}

The average thickness of coal seams in the Xucun coal mine was $6.6 \mathrm{~m}$, the immediate roof was a mixture of mudstone and sandstone and the thickness was about $3.7 \mathrm{~m}$, the main roof was siltstone and the thickness was about $15.6 \mathrm{~m}$, the floor was mudstone and the thickness was about $3 \mathrm{~m}$. The haulage roadway of repeated mining face was arranged in the coal pillar which width was $7 \mathrm{~m}$, after the excavation of the haulage roadway, the overburden load was transferred to the solid coal side of empty roadway and coal pillars on both sides of the haulage roadway broke down, as a result, the roof and the two sides of haulage roadway were destroyed more seriously. Therefore, in this case, the roof and the two sides of the roadway were the key points of support, because the roof and the two sides of the roadway were damaged more severely, they can be treated by grouting reinforcement. Therefore, the "anchor + anchor net + anchor cable" and grouting methods were proposed to ensure safe use of the roadway. When installing the anchor and anchor cable, installed the anchor dynamometers and monitored the anchor and anchor cable stress dynamically, and obtained figure 11 .

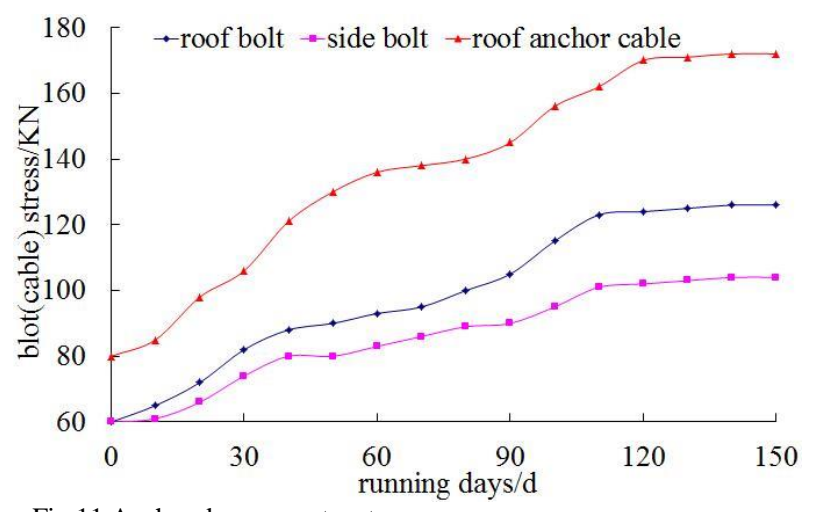

Fig.11 Anchor dynamometer stress

The curve shown in figure 11 was the anchor dynamometer readings within 5 months after installation of the anchor and anchor cable. From figure 11 it can be seen that the stress of the anchor and anchor cable was gradually rising, the maximum force of the anchor cable was $179 \mathrm{kN}$, which was $49.7 \%$ of the anchor cable breaking load of $360 \mathrm{kN}$; the maximum force of the anchor in roof was $120 \mathrm{kN}$, which was $54.5 \%$ of the anchor breaking load of $220 \mathrm{kN}$; the maximum force of the side anchor was $101 \mathrm{kN}$, which was $45.9 \%$ of the anchor breaking load of $220 \mathrm{kN}$. These data indicated that anchors and anchor cables were anchored in surrounding rock which was reinforced by grouting, and they had force foundation that can play an effective role in order to make the surrounding rock of roadway stable.

After the roadway was dug, monitored the deformation of surrounding rock of the roadway and recorded the displacement of the two sides and the displacement between the roof and the floor within 5 months, the observation results were shown in figure 12.

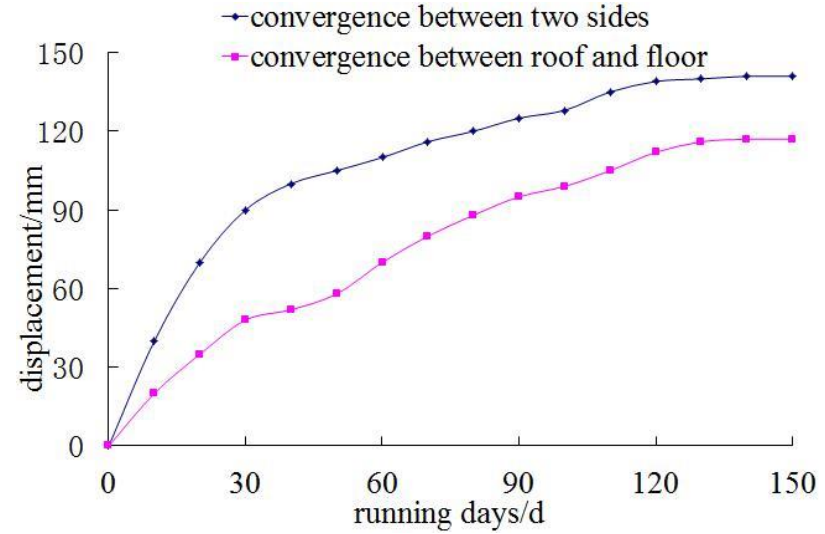

Fig.12 Surrounding rock displacement

It can be seen from figure 12 that roadway deformation was large within 30 days after excavation, and then the deformation trend was slowed down, and the deformation of surrounding rock tended to be stable in about 130 days. During the monitoring period, the displacement of the two sides was about $150 \mathrm{~mm}$, the displacement between the roof and the floor was about $120 \mathrm{~mm}$, and the deformation of the roadway was small, which did not affect the use of the roadway. The results showed that the bolt-grouting support method was used for the roadway excavated in the coal pillar, which can effectively maintain the stability of the roadway.

\section{CONCLUSIONS}

(1) Through the analysis of the stress distribution in the coal pillar which two sides was mined and the analysis of the stress distribution in the coal pillar when excavating roadway in this coal pillar, we can draw that excavating roadway in residual plastic pillar, the new roadway and the empty roadways constituted roadway group. The more denser of roadway was, the more larger of abutment stress was, when the residual coal pillar was destroyed due to its small size, the load on the coal pillar would be transferred to the adjacent coal pillar, if the adjacent pillar was damaged under the superimposed load, there would be a wide range of pressure arch in which overburden strata can move. In the research content of this article, the coal pillar was damaged, and the load on the coal pillar was transferred to the side of the solid coal. The maximum stress concentration factor in the solid coal was greater than the maximum stress concentration factor that there was no roadway.

(2) Through the self-developed grouting experiment system, an experiment study was conducted about the grouting reinforcement the surrounding rock of roadway, and 
it was concluded that the diffusion radius of the slurry and the strength of the grouting consolidation body when the grouting pressure and the slurry water-cement ratio were constant. Analyzed the reinforcing characteristics of slurry on plastic coal-rock mass: the cement slurry was infiltrated into the fractured coal-rock mass cracks under the action of the pressure of the grouting pump, and the cracks in the fractured coal-rock mass were filled and enriched. Due to the bond effect of the slurry, the fractured coal-rock mass was consolidated again and it formed a consolidation body that can play bearing capacity. Through the grouting of coal-rock mass, the strength and mechanical properties had been improved, so as to enhance the bearing capacity of surrounding rock of the roadway.

(3) By equivalently changing the mechanical parameters in the corresponding range of roadway surrounding rock and using FLAC3D numerical simulation, to study the stress and deformation damage of roadway surrounding rock under the conditions of bolt-grouting support, we can draw: the vertical stress value in coal pillar was significantly increased after bolt-grouting support, while the vertical stress value in the solid coal side of the old mining remaining roadway was significantly reduced, the plastic area of the surrounding rock of the new excavation roadway was significantly smaller, the roof new excavation roadway of was hardly damaged, the horizontal displacement of the two sides of the roadway was reduced by $70 \%$, and the amount of roof subsidence was reduced by $64 \%$, and the destruction depth of the solid coal side of the old mining remaining roadway was also reduced. After the surrounding rock of roadway was bolt-grouting supported, the slurry solidified the broken coal-rock mass and formed a solid body that had a bearing effect, the ability of coal pillar to carry overburden loads significantly improved, the coal pillar between the roadways, and the solid coal jointly beard the overburden load, the surrounding rock of roadway was in a stable state.

(4) It had been verified through engineering verification that the roadway adopted the bolt-grouting support, which can changed the mechanics parameters of surrounding rock of the roadway. The anchors and anchor anchors had force points, which can effectively reduce the deformation amount between the roof and floor and reduce the deformation amount between the two sides of roadway, maintained the stability of roadway surrounding rock effectively.

\section{ACKNOWLEDGMENT}

This work is supported by the National Natural Science Foundation of China (51379116) and the Natural Science Foundation of Shandong Province (ZR2016EEM36).

\section{REFERENCES}

[1] LU Gang. Research on residual coal workability evaluation and remaining technology of aged coalmine [D].XU Zhou: China University of Mining \& Technology, 2010.

[2] MENG Qingbin, HAN Lijun, QIAO Weiguo, et al. Numerical simulation research of bolt-grouting supporting mechanism in deep soft rock roadway [J]. Journal of Mining \& Safety Engineering, 2016, 30(1):27-34.

[3] WANG Yuanjie. Research on failure regularity and control technology of roadway surrounding rock in residual coal pillar [D]. TAI Yuan: Taiyuan University of Science and Technology, 2014.

[4] MA Qihua, WANG Yitai. Mechanism of narrow pillar protecting roadway and support technology of Gob-Side entry in deep mine [J]. Journal of Mining \& Safety Engineering, 2009, 12(4): 520-523.

[5] ZHANG Kexue, JIANG Yaodong, ZHANG Zhengbin, et al. Determining the reasonable width of narrow pillar of roadway in gob entry driving in the large pillar [J]. Journal of Mining \& Safety Engineering, 2014, 31(2): 255-262.

[6] LI Xiaoyu. Study on roadway in plastic pillar by numerical simulation [J]. Coal Technology, 2015, 34(9): 101-103.

[7] HAO Ruiyun, LI jianzhong, MA Fei. Numerical simulation research of driveling roadway in narrow of residual coal pillar [J]. Coal Technology, 2014, 33(8): 55-58

[8] ZHAO Guoxu, XIE Heping, MA Weimin. Study on stability of wide and thick coal pillar [J]. Journal of Liaoning Technical University, 2014, 12(1): 38-40.

[9] WANG Xujie. The Optimization and research on the reasonable size of coal pillar with fully mechanized caving in large dip angel and thick coal seam [D].TAI Yuan: Taiyuan University of Science and Technology, 2013.

[10] QIANG Minggao, SHI Pingwu, XU Jialin. Mining pressure and strata control [M].XU Zhou: China University of Mining and Technology Press, 2010.

[11] QIN Leyao, LIU Changwu, FANG Yanqiang. Research on expansive pressure arch theory and rock pillar load about the activity of the covered rock mass in close laneways [J]. Metal Mine, 2009, 26(12):20-24.

[12] LI Changdong, TANG Huiming, HU Xinli, et al. The rock similar material deformation and strength properties and numerical simulation study [J]. Geological Science and Technology Information, 2008, 18(6):98-101.

[13] YU Xinfeng, BAI Jianbiao. Research on grouting reinforced technology for broken coal wall of fully mechanized long wall mining face in Zhangji Mine [J]. Coal Science and Technology, 2006, 16(2): 69-71.

[14] Jiang Yaodong, Pan Yishan, Jiang Fuxing, Dou Linming, and Ju Yang. State of the art review on mechanism and prevention of coal bumps. Journal of China Coal Society, 2014, 39(2):205-213. 